\title{
Imbabura and Chimborazo at the cradle of Biogeography in the South American Andes
}

\begin{abstract}
The biogeographic profiles produced between 1802 and 1803 by Alexander von Humboldt and Francisco José de Caldas can be postulated as synchronous, though dissimilar, infographics, centered respectively on two volcanoes in Ecuador: Imbabura and Chimborazo. This short article presents documentary and iconographic evidence to support this appreciation.
\end{abstract}

Keywords: biogeography, andes, alexander von Humboldt, francisco josé de caldas
Volume 4 Issue 5 - 2020

\author{
Alberto Gómez Gutiérrez \\ Institute of Human Genetics, Pontificia Universidad Javeriana, \\ Colombia
}

Correspondence: Alberto Gómez Gutiérrez, PhD, FLS, Institute of Human Genetics, Pontificia Universidad Javeriana, Bogotá, Colombia, Email agomz@javeriana.edu.co

Received: August 27, 2020 | Published: October 22, 2020

\section{Introduction}

In the first months of 1803, both Alexander von Humboldt ${ }^{1}$ born in Prussia -nowadays Germany- and Francisco José de Caldas ${ }^{2}$ born in New Granada-nowadays Colombia- wrote independent manuscripts on biogeography under the respective titles of "Geography of plants" and "Levelling of plants". These manuscripts were supplemented by corresponding bio geographical profiles, each one drawn by their own hands. ${ }^{3}$

\section{Discussion}

Both Humboldt and Caldas, illustrated explorers in the turn of the $18^{\text {th }}$ to the $19^{\text {th }}$ century, had developed their bio geographical syntheses on two different volcanic milestones: Chimborazo in the case of Humboldt, and Imbabura in the case of Caldas. Their primary manuscripts support a simultaneous emergence and evolution of the concept of biogeography in the minds of the Prussian and the Neogranadian. In particular, the drawing entitled "Levelling of 30 species of plants on the western view of Imbabura, mountain near Ibarra" (Figure 1), should be understood as an alternative reference at the dawn of biogeography when compared with Alexander von Humboldt's "Tableau physique des Andes et pays voisins" (Figure 2), published in its engraved version in 1807 as an iconic illustration for his Essai sur la géographie des plantes près de l'équateur.

Documentary evidence indicates that Caldas' phyto geographic drawing on Imbabura would have been conceived at least a year and a half before its physical execution in the second semester of 1803. It sustains both the simultaneity and the implicit and explicit differences of pioneering approaches of Caldas and Von Humboldt to biogeography. Furthermore, Caldas would have started working in biogeography at least eight years before, as he explicitly registered 1796 as the year of his first measurements of plant geographical distributions while he traveled from Bogotá to Popayán.
On April 21 1802, after his personal acquaintance with Von Humboldt and Bonpland, Caldas proposed a project of botanical exploration to José Celestino Mutis, ${ }^{2}$ the leader of the Spanish Royal Botanical Expedition in the New Kingdom of Granada. In this proposal, In this proposal, he commented on the novelty of his idea of bio geographical research in the following terms: "Would not it be new, and at the same time beautiful, to divide into 12 zones of an inch in the barometer wide each, all the part of the earth that is able to vegetate? Would it not be new to assign to each plant its limits, and in a laconic and exact way to say: it inhabits the first zone, it inhabits from the third to the fifth, and so the others?"2

This idea had an experimental background, like the one Caldas himself referred to in an unpublished notebook of 1802 . Here, he made explicit his idea of the effect of latitude on the geography of plants, a notion that Von Humboldt would only publish in extenso in 1817one year after the death of Caldas-in his De distributionegeographica plantarum.

Caldas wrote a letter to Von Humboldt on his geographical and botanical works in Otavalo near Quito, on November 17, 1802. Was this report a stimulus for Von Humboldt forhis configuration and mailing from Guayaquil to José Celestino Mutis in February 1803-through the hands of Caldas-of the bio geographic profile of Chimborazo that he dedicated precisely to Mutis? This letter from Caldas came indeed into the hands of Von Humboldt, as it is now conserved in his legacy in Berlin, albeit incomplete.

By comparing the profiles of Caldas's Imbabura and Von Humboldt's Chimborazo, it should be noted that Caldas persistedmore than six months after having received Von Humboldt's drawingin his preliminary idea of dividing it into 12 inches. Caldas did not use any additional graphic elements from the Prussian's watercolor. The graphical syntheses of Caldas and Humboldt are, therefore, very different, although coincident in their bio geographical basis. 


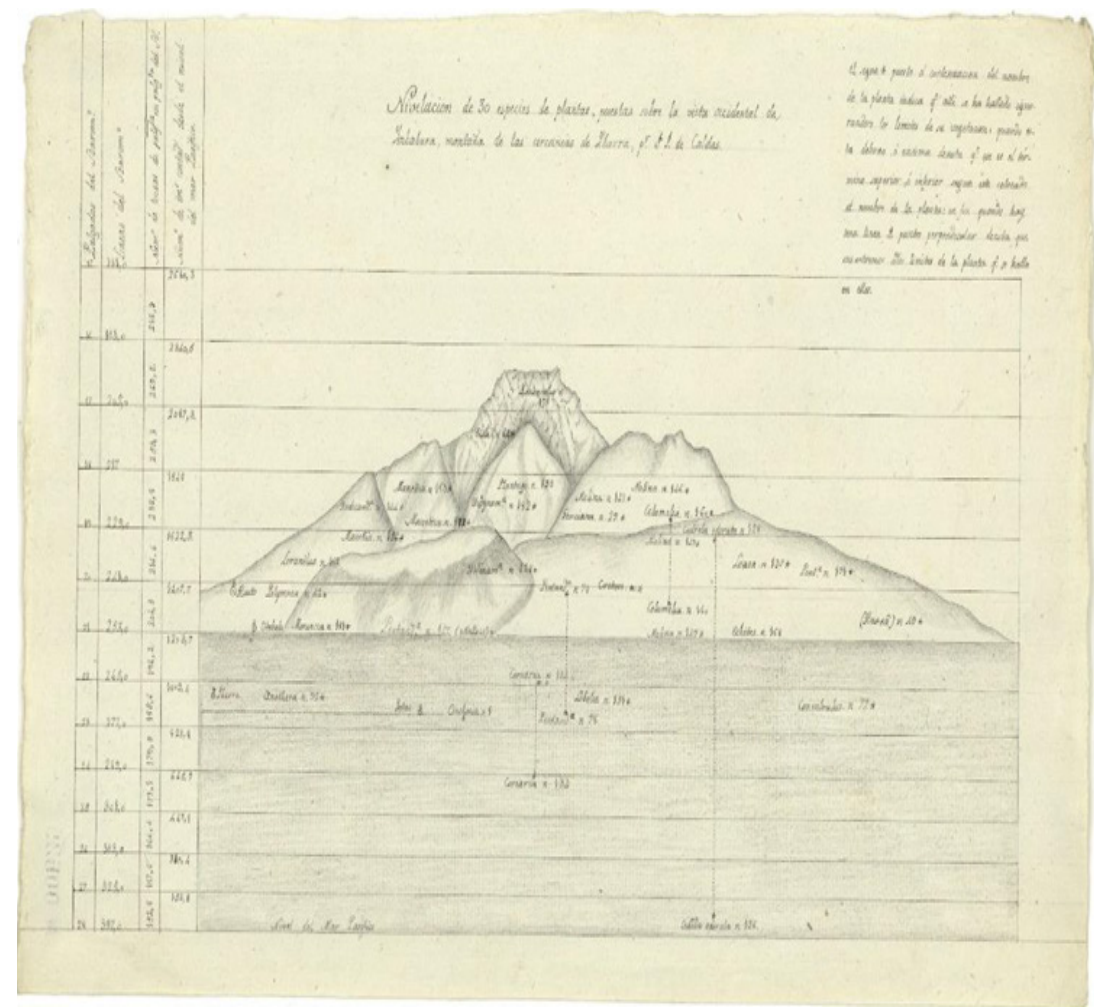

Figure I "Leveling 30 species of plants, on the western view of Imbabura, a mountain near Ibarra, by F. J. de Caldas" (I803). Archive of the Royal Botanical Garden of Madrid, AJB, Division III, M00529.

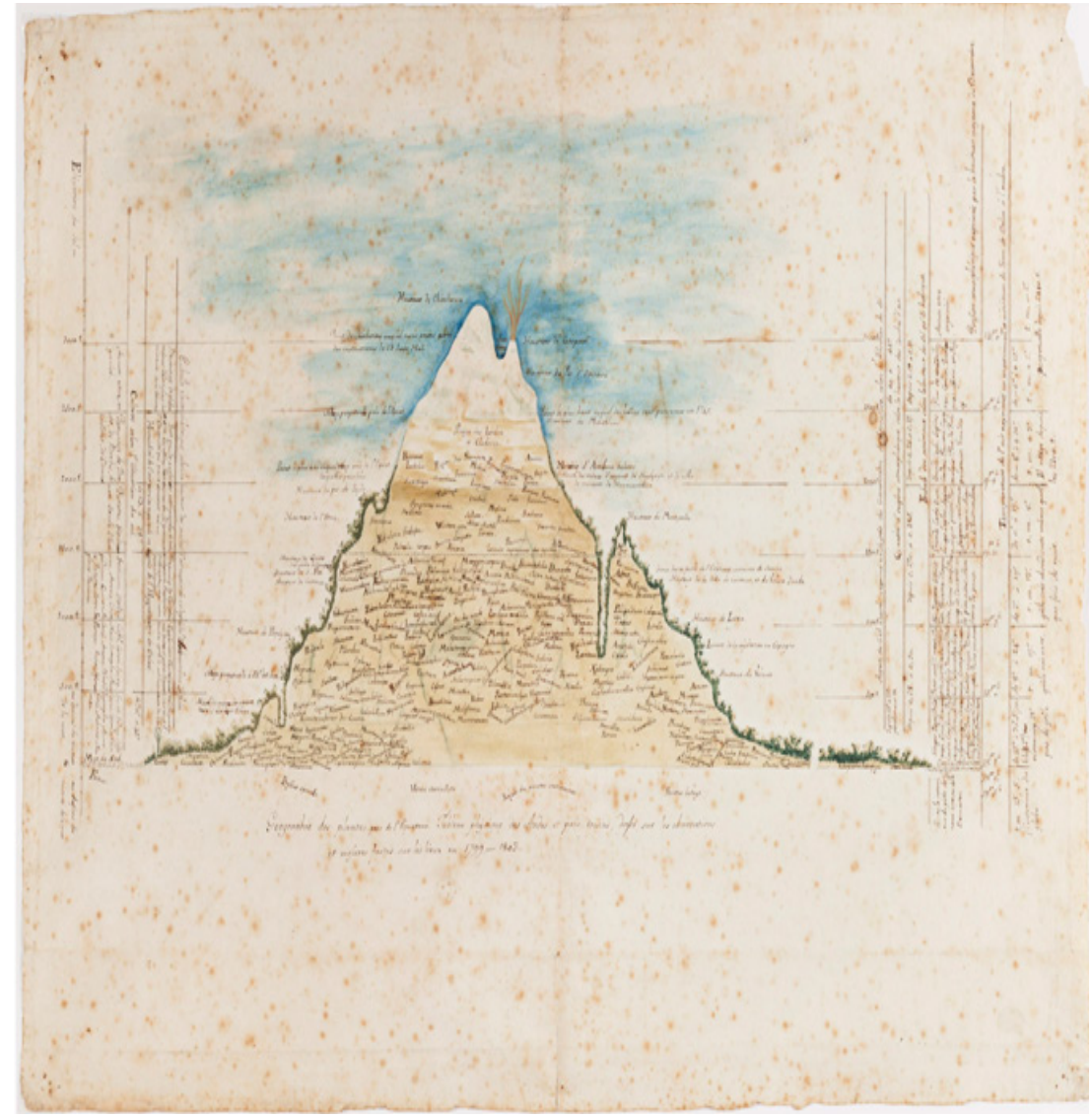

Figure 2 "Geography of plants near the equator. Physical table of the Andes and neighboring lands, based on observations and measurements made on the spot in I799-1803 "(1803). Museo Nacional de Colombia, MI204. 


\section{Conclusion}

The documentary evidence shown in this article, added to the notes and revisions that Caldas made on the work of Humboldt and published six years later in his Semanario del Nuevo Reyno de Granada in Bogotá, allows to support both the simultaneity and the implicit and explicit differences in the pioneering endeavors of Caldas and Humboldt in the field of biogeography.

\section{Acknowledgments}

None.

\section{Conflicts of interest}

Author declares that there is no conflict of interest.

\section{References}

1. Gómez Gutiérrez A. Alexander von Humboldt and transcontinental cooperation in the Geography of plants: a new appreciation of the phytogeographic work of Francisco José de Caldas. Internationale Zeitschriftfür Humboldt-Studien. 2016;17(33):22-49.

2. Caldas FJ. Memory on the plan of a projected trip from Quito to North America presented to the famous director of the New Granada Botanical Expedition, José Celestino Mutis. In: Arias de Greiff J, Bateman A, editors. Complete works of Francisco José de Caldas. Bogotá: National University of Colombia. 1966.

3. Gómez Gutiérrez A. Humboldtiana neogranadina. 2018. 